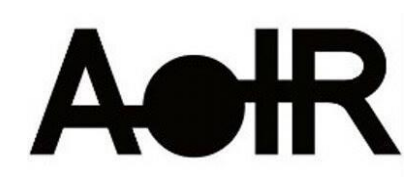

Selected Papers of \#AoIR2020:

The 21st Annual Conference of the

Association of Internet Researchers

Virtual Event / 27-31 October 2020

\title{
NOVEL, EDUCATIONAL AND LEGAL RESPONSES TO TECHNOLOGY- FACILITATED SEXUAL VIOLENCE
}

\author{
Pauline Sameshima \\ Lakehead University \\ Rebecca Katz \\ McGill University \\ Shareen Shariff \\ McGill University \\ Christopher Dietzel \\ McGill University
}

\begin{abstract}
The three panel presenters and session chair are co-researchers in a seven-year research partnership-involving 28 educational institutions, 25 co-investigators, 15 community partners, and $50+$ students-that aims to address sexual violence in physical and virtual forms in university contexts across Canada and internationally. The project specifically seeks to address, dismantle and prevent sexual violence by means of multi-sector partnership solutions across the fields of education, law, policy, arts, popular culture, health care, management, news and social media. Using the methodological framework of Parallaxic Praxis (Sameshima et al., 2019), the team looks at a phenomenon from different perspectives by using varied methodological processes as well as a range of rigorous methods of encoding, decoding, and rendering data; and establishing post-qualitative possibilities for generating and mobilizing knowledge to broader audiences. The juxtaposition of renderings (constructions made from deep analysis of the phenomena such as papers, presentations, artworks, and other artefacts), when presented together, manufacture a dynamic agency between works capturing intertextualities, aporias, choruses, and a poesis that arise in the coalescence of the unassimilated, individual investigations. In this panel, an overview of the larger project and the significant milestones in the first four years specifically related to internet technologies will be provided. Drawing from multi-perspectives, the second presenter
\end{abstract}

Suggested Citation (APA): Sameshima, P., Katz, R., Shariff, S., Dietzel, C.,(2020, October). Novel, Educational and Legal Responses to Technology-Facilitated Sexual Violence. Panel presented at AolR 2020: The 21th Annual Conference of the Association of Internet Researchers. Virtual Event: AolR. Retrieved from http://spir.aoir.org. 
will address image-based sexual abuse and copyright in Canada, and the third will share data collected from this project in the form of excerpts from an epistolary novel. The session demonstrates how multi-modal investigations and dissemination offer possibilities for extending knowledge production.

\section{Panel Outline}

Responding to sexual violence-a regrettably widespread problem in the early $21 \mathrm{st}$ century-requires broad cultural shifts and efforts of many stakeholders. The relevance of certain disciplines or practice areas, such as criminal law and applied social sciences like social work or psychology researching this phenomenon, may be more immediately apparent; however, sexual violence pervades many, if not all, aspects of our society. Sexual violence has increasingly found a home on the internet, which houses and amplifies misogyny, homophobia and transphobia, racism, and other intersecting forms of discrimination (Shariff, 2017). Kircaburun and Griffiths (2018) report the positive relationship between dark personality traits such as Machiavellianism, psychopathy, narcissism, sadism, and spitefulness with problematic internet use (PIU). PIU has been described as internet dependency, internet addiction, and internet use disorders (Kuss, et al., 2014). Further, the internet facilitates gender-based and sexuality-based harm through online and in-person interactions (Henry \& Powell, 2016). The internet additionally allows for what Suler (2005) refers to as the 'online disinhibition effect', when social expectations and inhibitions are loosened in internet-mediated interactions compared to expectations when in face-to-face communications. The relaxation of inhibition exaggerates and creates new challenges related to cyberbullying, discrimination, and consent, such as image-based sexual abuse (i.e., revenge porn) and sexual harassment.

How can digital communities address technology-facilitated sexual violence? How do formal systems like education, psychology, and law implement interventions that minimize such violence? This panel draws from danah boyd's (2010) concept of 'networked publics' to consider how internet-goers confront such violence, and also applies interdisciplinary frameworks and arts integrated approaches to explore deeply rooted cultural beliefs, quotidian practices, and identity politics; and further, to propose institutional responses.

The session presenters scrutinize social systems in an effort to reorient services, pedagogical approaches, and interpersonal relations toward an ethics of care.

Acknowledging that sexual violence is a complex, deep-rooted issue that requires a multi-faceted approach, the presenters explore the possibilities of change from multiple perspectives, including through interdisciplinary approaches, disciplinary interventions, innovative methodological approaches, various support services, and online communities. Presenters will recommend strategies for addressing sexual violence that are evidence-based, culturally-sensitive, and interdisciplinary.

Following cultural communication theorist Stuart Hall's (1973) work on encoding and decoding, the varied ways researchers encode data allow for the varied possibilities of decoding or generating new creative responses to data. As such, this session highlights 
novel and interdisciplinary work that aims to better understand the role of the internet in abusive attachments, and improve institutional supports, public education, and legal responses to sexual violence related to online contexts.

The first presentation in this panel features the Principal Investigator in the research partnership noted above. It describes in more detail the milestones of the partnership's first four years, as well as its methods and goals. This presentation canvases the legal obligations incumbent on institutions to address and prevent sexual violence, both onand off-line. The second presentation addresses a narrower branch of law and its potential application to one sub-category of online sexual violence, 'revenge porn.' This presentation considers copyright law's utility in mitigating revenge porn in which victims see their selfies exploited by others. The presenter discusses the relevance of copyright law in Canada and internationally, and presents preliminary findings from Canadian case law. Finally, the third presentation shares excerpts from an in-progress epistolary novel that highlights themes on digital identity creation in tandem with online disinhibition effects, patriarchy and nostalgia's contributive role in online abuse, and the semiotic slip of meanings and words in text-based environments. The three panelists demonstrate how the juxtaposition of non-assimilated research investigations offer unique possibilities for extending knowledge production.

\section{References}

Boyd. D. (2010). Social network sites as networked publics: Affordances, dynamics, and implications. In A networked self (pp. 47-66). Routledge.

Hall, S. (1973). Encoding and decoding in the television discourse. University of Birmingham. Retrieved from https://www.birmingham.ac.uk/Documents/collegeartslaw/history/cccs/ stencilledoccasionalpapers/1to8and11to24and38to48/SOP07.pdf

Henry, N., \& Powell, A. (2018). Technology-facilitated sexual violence: A literature review of empirical research. Trauma, Violence, \& Abuse, 19(2), 195-208.

Kircaburun, K., \& Griffiths, M. D. (2018). Instagram addiction and the Big Five of personality: The mediating role of self-liking. Journal of Behavioral Addictions, 7(1), 158 170.

Sameshima P., Maarhuis, P., \& Wiebe, S. (2019). Parallaxic praxis: Multimodal interdisciplinary pedagogical research design. Vernon Press.

Shariff, S. (2017). Navigating the minefield of sexual violence policy in expanding "University Contexts." Education \& Law Journal, Vol. 27.1 (1-17). (37-58).

Suler, J. (2005). The online disinhibition effect. International Journal of Applied Psychoanalytic Studies, 2(2), 184-188. 
Panel Speaker 1

\title{
NAVIGATING LEGAL AND EDUCATIONAL POLICY DILEMMAS OF ONLINE SEXUAL VIOLENCE: IMPACTS THROUGH MULTI-SECTOR PARTNERSHIP
}

\author{
Shaneen Shariff \\ McGill University
}

\section{Rationale and Background}

The proliferation of sexually offensive communication including cyberbullying; intersecting threats of sexual, misogynist, homophobic and racist physical violence; non-consensual distribution of intimate images, online extortion; sexist and homophobic jokes, demeaning and modified photographs on social media ("online sexual violence") has, over the last two decades, resulted in significant dilemmas for legislators and educational policy-makers (Backhouse, et al., 2015; Patel, 2014; Garcia \& Vemuri, 2017). The challenge comes in balancing free expression rights versus public safety, given that social media intermediaries are generally reluctant to take down offensive posts. Educational administrators are hesitant to discipline alleged online perpetrators regardless of whether they are from the institutional community, arguing that they should only realistically be held responsible for monitoring conduct/misconduct on campus (Blinded). This is further complicated when generations of students (GenX,Y,Z) are growing up in an era of officially sanctioned on-and-off-line hate, fake news and protectionism. Researchers observe that online sexual violence often translates into physical space playing out as sexual assault and rape in extreme cases (Garcia \& Vemuri, 2017; Benedict, 1993). Online sexual violence has spread insidiously and globally, often with devastating consequences to young people, especially young women (Wolak et al., 2018). Institutional responses need to be proactive, informed and cohesive to reduce and prevent sexual violence (Backhouse et al, 2015).

\section{Focus of Presentation}

This presentation clarifies institutional legal responsibilities on-and-off-line, explaining that North American courts have long established an obligation for educators to respond to cyberbullying and online sexual violence if there is a nexus to the university community ("University Context") (Blinded). Dilemmas that confront public policy makers in an online society evolving too rapidly for laws to keep up will be highlighted. This presentation introduces a multi-disciplinary, multi-partnered research partnership that adopts an innovative, collaborative approach to sexual violence. The project is funded for 7 years by the Social Sciences and Humanities Research Council of Canada (SSHRC) for $\$ 2.5$ million dollars, together with Partner contributions of $138 \%$ of that amount. 
This project has grown out of the Pl's significant research on sexual violence and cyberbullying; addressing the intersections of law and education; and increasingly blurred lines between free expression rights, safety, censorship, privacy, protection and civic responsibility. With 28 university partners; 25 co-investigators; 15 community partners and $50+$ students engaged, this project is poised towards developing broad, deep and sustainable impacts in society that are centered on community engagement and agency, and collaboration with multi-sector partners from education, law, arts, media, health care and management. This presentation will focus on the milestones achieved in this project in its first four years.

\section{Methodological Framework}

The partnership uses multi-disciplinary and mixed-methods as part of three subprojects, addressing three areas:

Project A: Law and Policy: How do educational and legal institutions create barriers to reducing sexual violence and what are the legal responsibilities of universities to prevent it?

Project B: How do social media and popular culture tacitly condone sexual violence and how can they be mobilized to effect change?

Project C: How does the news media tacitly condone sexual violence and how can it be mobilized to effect change?

At the heart of these projects is emphasis on the need for non-arbitrary, evidence-based policies, procedures that adhere to due process and procedural fairness; and integrated, multi-disciplinary educational programs and curricula that reclaim the role of schools and universities to educate not only their own students, but ultimately greater society. Specifically, our methodologies include:

Project A: Law and Policy:

- Climate studies of sexual violence were distributed to 24 universities in Canada and 4 international universities. Based on a pilot study completed at McGill University in 2018, a survey of 28 universities is now being launched.

- Literature reviews and critical legal literacy including legal case law and statutory analysis; criminal justice reform and analysis of civil law responses culminating in two White Papers for university administrators.

Project B: Role of Arts, Activism and Popular Culture

- Enhancing student and public engagement through dialogue and the arts (theatre; art galleries, music lyrical analysis). We have developed theatre productions, hosted art exhibits engaging feminist artists from several communities; videos, documentaries, animation, and workshops (Buckingham \& Sefton-Green, 1994).

Project C: Role of News and Social Media 
- Critical media analysis of media reports to analyze ways in which framing of news stories on sexual violence re-victimize and provide enhanced platforms to trolls and sexual violence perpetrators (Hoeschmann \& Poyntz, 2012).

Student Mentorship Committee: The success of this project involves the engagement of students whereby the $\mathrm{PhD}$ students work with Masters and undergraduate students to drive and engage in research; write and co-publish papers and co-present at international and national conferences; collaborate with arts and media institutions and take on internships with sector partners.

\section{Conclusion and Implications}

During our first four years we have achieved significantly more milestones than expected at the outset, and this is due to the student leadership, ownership and passion for addressing sexual violence in ways that draw on student perspectives and experiences. The creative combined aspects of theatre, arts and law provide a unique and interesting approach to the issues, enabling ally-ship of males who may adhere to patriarchal, androcentric perspectives. The project addresses homophobia and transgender experiences, and we are embarking on research on the extent and impacts of sexual violence on young people with disabilities in educational contexts. We have a doctoral study underway of the experiences of international students with sexual violence, providing a broad overview. Our approach shows greater promise of informed, non-arbitrary and isolated responses to sexual violence, that we hope to share with delegates at the conference.

\section{References}

Backhouse, C., McRae, D., lyer, N. (2015). Report of the task force on misogyny, sexism, homophobia in Dalhousie University Faculty of Dentistry. Retrieved from: http:// www.dal.ca/content/dam/dalhousie/pdf/cultureofrespect/DalhousieDentistryTaskForceReport-June2015.pdf

Buckingham, D., \& Sefton-Green, J. (1994). Cultural studies goes to school: Reading and teaching popular media. Taylor \& Francis.

Benedict, H. (1993). The language of rape. In E. Buchwald, P. R. Fletcher, \& M. Roth (Eds.), Transforming a rape culture (pp. 101-105). Milkweed.

Garcia, C., \& Vemuri, A. (2017). Theorizing "rape culture": How law, policy and education can support and end sexual violence. Education \& Law Journal, 27(1), 1-17.

Hoechsmann, M., \& Poyntz, S.R. (2012). Media literacies: A critical introduction. WileyBlackwell.

Kelly, L. (2013). Surviving sexual violence. John Wiley \& Sons. 
Patel, A. (2014, October 30). 460,000 sexual assaults in Canada every year: YWCA Canada. Huffington Post Canada. Retrieved from http://www.huffingtonpost.ca/ 2014/10/30 sexual-assault-canada_n_6074994.html?

Shariff, S. (2017). Navigating the minefield of sexual violence policy in expanding "university contexts." Education \& Law Journal, Vol. 27(1), 37-58.

Shariff, S. (2015). Sexting and cyberbullying: Defining the line on digitally empowered kids. Cambridge University Press.

Sheppard, C. (2010). Inclusive equality: The relational dimensions of systemic discrimination in Canada. McGill-Queen's Press-MQUP.

Wolak, J., Finkelhor, D., Walsh, W. A., \& Treitman, L. (2018). Sextortion of minors: Characteristics and dynamics. Journal of Adolescent Health, 62, 72-79.

Panel Speaker 2

\section{REVENGE PORN AND COPYRIGHT: A PRELIMINARY STUDY OF CANADA'S LEGAL LANDSCAPE}

Rebecca Katz

McGill University

\section{Introduction}

Sexual violence, including 'revenge porn', has become common on the internet, with severe adverse impacts on victims. Legal systems like Canada's are playing catch-up with this challenge. Civil lawsuits and criminal prosecutions, including under a new Criminal Code provision, offer Canadian victims some recourse; however, copyright law has been touted elsewhere as an unexpected addition to victims' legal toolkit. Given the harms of 'revenge porn' and the frequent difficulty of getting these images removed, additional tools are welcome. This presentation first reviews the problem of 'revenge porn' and the relevant topography of Canada's legal landscape. It then addresses the presenter's preliminary findings on Canadian copyright's relevance.

\section{Methods}

The presenter conducted a case law search in the CanLii legal database. Combinations of the search terms "intimate images," "nude," "sexting," "revenge porn," "copyright," "cyberbullying," and "infringement" were searched. Finally, the presenter analyzed relevant parts of Canada's Copyright Act.

\section{Background}

Revenge porn, a term which has been criticized for victim-blaming and/or obscuring incidents where images are created without victims' knowledge or consent (McGlynn et al., 2017), is one form of image-based sexual abuse (Maddocks, 2018; McGlynn, 
Rackley \& Houghton, 2017). Image-based sexual abuse (IBSA) can occur, among other scenarios, when a partner, former partner, or third-party distributes or posts a sexual photo of a person without their consent (Haynes, 2018). Victims of this exploitation experience adverse impacts similar to those experienced by sexual assault victims, including trauma, victim-blaming, and harassment (Bates, 2017). While challenging to determine the prevalence of IBSA, a meta-analysis found rates ranging from $0.5 \%$ to $42 \%$ (Walker \& Sleath, 2017). Overall, research has shown that IBSA is a concern among teens and young adults, that victims can be any gender, and that sexual minorities and other marginalized persons may face higher risks (Henry \& Powell, 2019 Walker \& Sleath, 2017).

\section{Legal landscapes}

Concern about IBSA has inspired legal responses. Canada's child pornography laws can be used to prosecute perpetrators when victims are under eighteen (Bailey \& Hanna, 2011), but are inapplicable to adult victims. In 2015, however, Canada's Parliament amended the Criminal Code and adopted a new offense of non-consensual distribution of intimate images, regardless of the victim's age (Criminal Code, s. 162.1). Likewise, victims have used several civil causes of action to sue perpetrators for damages in Canadian courts, including breach of confidence and invasion of privacy actions (Haynes, 2018; Slane, 2013).

Unfortunately, even successful prosecutions or lawsuits against perpetrators may not remove harmful images from the Internet. US law provides broad immunity for web hosts for user-submitted content, with exceptions for child pornography and for copyright infringement of which the host receives notice (Folderauer, 2014; Penney, 2013). Canadian law likewise offers Internet services immunity. For example, Canada's Copyright Act requires only that service providers and search engines receiving notice of infringement forward the notice to the subscriber allegedly responsible (Copyright Act, s. $41.25(1))$.

Nonetheless, copyright law has been proposed as another tool for victims of IBSA who created the images themselves (Folderauer, 2014; Lee, 2019). Commenters have pointed to the relatively low barriers to submitting a copyright takedown notice to a web host, who, under US law, is expected to remove the infringing content (Folderauer, 2014; Levendowski, 2014).

\section{Findings}

In Canada, creators of works automatically hold copyright; no registration is required to assert one's rights. Further, selfies could meet the low threshold needed to be copyrighted (see e.g. CCH Canadian Limited v. Law Society of Upper Canada, 2004 SCC 13). These factors could help victims of IBSA whose self-created images are being exploited. Moreover, it seems unlikely that Canada's fair dealing provisions, with their narrow list of lawful purposes, could protect IBSA in which perpetrators misuse victims' selfies. 
As of this writing, the presenter found no Canadian case law in which copyright claims were used to address IBSA. None of the search terms yielded reported cases where a victim made a claim in copyright. The search string "cyberbullying AND copyright" yielded one case, in which plaintiffs requested that the defendant's copyrights in cyberbullying posts be transferred to them (Clancy v. Farid, 2018). The substantive issues in that case have not gone to trial, and no judgement respecting the copyright question has been issued. Further, those facts have limited relevance to IBSA victims who hold copyright in selfies, though a precedent transferring the copyright may help victims of other online harassment.

\section{Discussion}

While no cases reported in CanLii use copyright to address IBSA, this does not mean that copyright is irrelevant in this context. It is possible that unreported cases, or cases in other databases, make this connection. Further, copyright notices are submitted to a web host or service provider-not a court. While applicable law is a thorny issue in copyright matters, it is possible that victims, including Canadians, are already filing notices. That remedy may be especially effective against US-based platforms, such as the social media giants, which have formal takedown procedures. However, these practices are difficult to observe using case law data.

This research is significant as an exploratory study of whether copyright has been used to help Canadian victims of IBSA. Future research should explore other databases and address the uses of copyright to combat IBSA in other jurisdictions, where such actions may have been pioneered. Empirical work with stakeholders about their knowledge of legal tools is also desirable, as copyright and other legal actions may be poorlyrecognized by the public.

\section{References}

Bailey, J., \& Hanna, M. (2011). The gendered dimensions of sexting: Assessing the applicability of Canada's child pornography provision. Canadian Journal of Women and the Law, 23(2), 405-441.

Bates, S. (2017). Revenge porn and mental health: A qualitative analysis of the mental health effects of revenge porn on female survivors. Feminist Criminology, 12(1), 22-42. https://doi.org/10.1177/1557085116654565

Clancy v. Farid, 2018 ONSC 7482

Copyright Act, R.S.C., 1985, c. C-42

Criminal Code, R.S.C., 1985, c. C-46

Folderauer, K. M. (2014). Not all is fair (use) in love and war: Copyright law and revenge porn comment. University of Baltimore Law Review, 44(2), 321-340.

Haynes, J. (2018). Judicial approaches to combatting revenge porn: A multijurisdictional perspective. Commonwealth Law Bulletin, 44(3), 400-428. 
Henry, N., Flynn, A., \& Powell, A. (2019). Image-based sexual abuse: Victims and perpetrators. Trends \& Issues in Crime and Criminal Justice, March 2019(572), 1-19.

Lee, Y. H. (2019). Delivering (up) a copyright-based remedy for revenge porn. Journal of Intellectual Property Law \& Practice, 14(2), 99-111. https://doi.org/10.1093/jiplp/jpy122

Maddocks, S. (2018). From non-consensual pornography to image-based sexual abuse: Charting the course of a problem with many names. Australian Feminist Studies, 33(97), 345-361. https://doi.org/10.1080/08164649.2018.1542592

McGlynn, C., Rackley, E., \& Houghton, R. (2017). Beyond 'revenge porn': The continuum of image-based sexual abuse. Feminist Legal Studies, 25(1), 25-46. https:// doi.org/10.1007/s10691-017-9343-2

Penny, J. (2013). Deleting revenge porn. Policy Options. Retrieved from https:// policyoptions.irpp.org/fr/magazines/vive-montreal-libre/penney/

Walker, K., \& Sleath, E. (2017). A systematic review of the current knowledge regarding revenge pornography and non-consensual sharing of sexually explicit media. Aggression and Violent Behavior, 36, 9-24. https://doi.org/10.1016/j.avb.2017.06.010

\section{Panel Speaker 3}

\section{MAKING LOVE-THE SIMULACRA OF CONSENT}

Pauline Sameshima

Lakehead University

Framed within the research methodology of Parallaxic Praxis (Sameshima et al., 2019), this presentation panel positions three speakers together with the deliberate aim to trouble the boundaries of research disciplinarity, funds of knowledge, and research modality while studying the same phenomenon.

This panelist focuses on identity construction, attachment development, and critical cultural and curriculum theory, using excerpts from an epistolary novel in process. Specifically, slippings in semiotic signs (i.e., words having different meanings) and precession of simulacra (Baudrillard, 1994; i.e., the development of representations of the real) are basis points for how internet communication promotes mutability of identities and meaning-making. The epistolary format is used because genre and form have the power to offer readers experiences that appear believable and valid (Kvale, 1995). The rendering of research determines the reach of the audience and is "the main vehicle through which our scholarship becomes known and, for that matter, widely accepted or rejected by peers" (Cole and Knowles, 2001, p. 122).

\section{Excerpts}

Feb 21--Sent 
Dear James,

Of course, I'm not going to use your real name in the book. Ha! I just realized I was talking about James, the name you wanted, not your real-real name on our joint Royal Bank account. It is interesting I suppose. I think of you as James. I say "I love you, James." When I use your passport name, you've said I sounded stern, not as loving. No one knows I call you James. Is that a red flag?

I've wondered about naming, how research participants choose their pseudonyms, how people mask their names online, create new identities, say things they would never say if people knew who they were. Cancel culture is real. Do you remember when we made up names for each other? Was that the first lie? Or was it when you said you were single when you weren't? You hardly use the name you made up for me. You always call me darling. I think it's because you have no name for me. Maybe my name never mattered to you, or maybe the word "darling" means way more to me than you. Or maybe you use "darling" for everyone secretly.

The time you left your phone on the counter with your messages app open, I saw that you had named me R2000, a reference number, from the short story I made up about us. You gave me a name like a unit model, not like when you said you were infatuated with her because she looked like a model. You actually said that to me? You wanted to text me secretly, leave no trace so you made up names for us. That first day, making up names seemed fun, not permanent.

Feb 22--Sent

\section{Dear James,}

I've got a name for the book! Making love-Changing the World. What do you think? I was talking about making, how creative generation and gifting builds relation and love and thus changes the world. Also, it refers to generating love, trying to get people to love us, that causes us to create fake selves, idealized selves, and this is what is changing the world in a dark way. The fake self is like a simulacrum. I'm going to copy my explanation here for you. I used it in last week's grad class blog.

A simulacrum is a representation of something that becomes the perceived real. Baudrillard's (1994) opening in Simulacra and Simulations recounts an allegory by Luis Borges in which cartographers map out the Empire with so much detail, the replication is mistaken for the original. Over time, as the map and territory coalesce in decay and the inhabitants no longer know the difference between the map and the territory, they find themselves disoriented. Precession of simulacra refers to the constructed symbol or sign eclipsing or preceding and even determining the original. (Sameshima, 2017, p. 3)

It's really about creating a fake identity. People present this ideal self that appears so much better than who they really are. I think Baudrillard's work aptly explains that when the fake self is successful, then it's really easy for the base to become veiled or lost. 
Feb 23 - Unsent

Dear James,

I just read Twenge and Campbell's (2009) The Narcissism Epidemic. Various studies confirm correlations between self-esteem, narcissism and internet use (Kircaburun \& Griffiths, 2018). Higher levels of narcissism are positively associated with Facebook use (Walters \& Horton, 2015) specifically with the number of self-focused sends about the self and larger numbers of Facebook friends (McKinney, Kelly \& Duran, 2012). This all makes sense. Narcissistic personality disorder includes the creation of a false self, a simulacrum of the true self because the authentic self is not deemed valuable or good enough. The presented false self is much shinier, armoured.

March 15 unsent

Dear James,

I did one of those online surveys. I am the perfect match for the narcissist. Saeed (2019) says that high achieving intelligent people are often victims of narcissists because of soft and flexible boundaries. Being open minded, non-judgemental and questioning are usually deemed admirable traits, but these are exactly the traits that make me vulnerable.

Did you open the link I sent? It's on the Ipsos Global Trends survey (Emes, 2017). The survey says there is a shift toward nostalgia and tradition, and a slowing movement toward more liberal attitudes. This seems backwards to me. In response to the statement: The role of women in society is to be good mothers and wives, there was a significant increase in agreement in 12 of the 22 countries surveyed on this measure. Do you know what this means? It's saying that the world is moving toward more traditional conservative stances. I suppose it's not that surprising. The world wants more stability. I suppose stability of an impostered identity is foolish to ask for when we keep developing our relationships and identities online.

\section{References}

Baudrillard, J. (1994). Simulacra and simulation (S. F. Glaser, Trans.). University of Michigan Press.

Cole, A. L., \& Knowles, J. G. (2001). Qualities of inquiry. In L. Neilsen, A. Cole \& J. G. Knowles (Eds.), The art of writing inquiry. Backalong Books. 
Emes, C. (2017). Ipsos global trends. The changing role of women. Global Trends 2020. https://www.ipsosglobaltrends.com/the-changing-role-of-women/

Hall, S. (1973). Encoding and decoding in the television discourse. University of Birmingham. https://www.birmingham.ac.uk/Documents/college-artslaw/history/cccs/ stencilled-occasional-papers/1to8and11to24and38to48/SOP07.pdf

McKiney, B. C., Kely, L., \& Duran, R. L. (2012, April). Narcissism or openness?: College students' use of Facebook and Twitter. Communication Research Reports, 29 (2): 08-118. https://doi.org/10.1080/08824096.2012.666919

Kircaburun, K., \& Griffiths, M. D. (2018). The dark side of internet: Preliminary evidence for the associations of dark personality traits with specific online activities and problematic internet use. Journal of behavioral addictions, 7(4), 993-1003. https:// doi.org/10.1556/2006.7.2018.109

Kvale, S. (1995). The social construction of validity. Qualitative Inquiry, 1(1): pp. 19-40). doi:https://doi.org/10.2174/13816128113199990617

Twenge, J. M., \& Cambell, W. K. (2009). The narcissism epidemic. Atria.

Sameshima, P. (2017, December). Post-truth simulacra: Inviting mutable meaningmaking. Journal of the Canadian Association for Curriculum Studies, 15(2), 1-5.

Sameshima P., Maarhuis, P., \& Wiebe, S. (2019). Parallaxic praxis: Multimodal interdisciplinary pedagogical research design. Vernon Press.

Saeed, K. (2019). Emotional abuse and 7 signs of covert narcissism. https:// kimsaeed.com/2015/05/02/emotional-abuse-and-covert-narcissism/

Walters, T. W., \& Horton, R. (2015). A diary study of the influence of Facebook use on narcissism among male college students. Computers in Human Behavior, 52: 326-330. https://doi.org/10.1016/j.chb.2015.05.054 